\title{
Estudio clínico e histológico de la cicatriz de la cesárea segmentaria
}

\author{
Eduardo Acosta Bendek*
}

RESUMEN: Se hace un estudio clínico e histológico de 64 cicatrices de cesáreas anteriores con la técnica de una sola sutura, con puntos separados. Se encontró una regeneración normal de tejido muscular de la cicatriz, en el $67 \%$ del total de los casos. Se comprobó que a medida que aumenta el número de cesáreas el tejido muscular va siendo reemplazado por tejido fibroso y hialino. Se recomienda la atención del parto por vía vaginal después de la primera cesárea con la técnica anterior, teniendo en cuenta los requisitos exigidos en la evaluación de estos casos.

Después de la segunda cesárea se aconseja la vía abdominal como la más indicada.

PALABRAS CLAVES: Cicatriz buena, regular, mala; segmento uterino; una sola sutura, puntos separados.

SUMMARY: A clinical and a histological study is done on 64 cesarean previous scars with the technic of only one suture, with separate stitches. A normal regeneration of the muscular tissue was found in a $67 \%$ of the total cases. It was proved that, as the number of cesarean section increases, the muscular tissue starts to be replaced by fibrous and hyaline tissue. It is recomended the attention of labor via the vagina after the first cesarean section with the previous technic having in consideration all requirements in the evaluation of these cases.

After the second cesarean, it is advised the abdominal via as the most indicated.

KEY WORDS: Good scar, regular, bad; uterine segment; one suture only.

\section{Introducción}

El uso de la doble sutura del segmento uterino en la cesárea segmentaria, una sutura perforante continua y la otra invaginante, recomendada por el obstetra alemán Keherer en 1882 , con el fin de evitar la salida de los loquios a la cavidad peritoneal, y de esta manera prevenir el riesgo de una peritonitis con su consiguiente mortalidad materna. Esta técnica fue muy bien acogida por los obstetras de esa época y de la presente, ya que es la técnica quirúrgica que se ha venido practicando hasta la presente, con escasas modificaciones.

La alta incidencia de defectos de la cicatriz del segmento uterino, como la dehiscencia y la ruptura de éste $(1,5)$ es originada por la isquemia a nivel del segmento, como consecuencia de la doble sutura. Esta deficiencia de mala cicatrización produjo un cambio de concepto en la conducta de la paciente cesareada, en que una vez cesárea, siempre cesárea, concepto éste que se convirtió casi en un hábito a partir de la década del 70, como lo comprueban las estadísticas nacionales y extranjeras así: en el año de 1970 se registró una incidencia de cesárea de $6.3 \%$ y en el año de 1990 ha sobrepasado el $31.8 \%$ (6).

Conducta ésta que no tiene justificación en la obstetricia moderna, ya que los grandes avances de la ciencia y la tecnología nos proporcionan un mejoramiento en la técnica quirúrgica, en la anestesia, en la seguridad de las transfusiones, en la disponibilidad de una gama de antibióticos y suturas etc., lo que permite la ejecución de un procedimiento quirúrgico sin complicaciones intra y post-operatorias; si a lo

* Rector Universidad Metropolitana. Profesor Titular de Ginecobstetricia anterior le agregamos la modificación de la técnica quirúrgica propuesta en este escrito, de cerrar el segmento uterino con una sola sutura, con puntos separados, obtendremos una mejor irrigación de éste,-además del uso profiláctico de antibióticos. Todo lo anterior redundará en una regeneración muscular normal de la cicatrización del segmento, obteniendo de esta manera que el futuro obstétrico de la paciente sea mejor, lo que dará más seguridad para la atención del parto por vía vaginal, siempre y cuando la indicación de la cesárea anterior fuera por causas relativas (3).

Esta técnica la hemos venido recomendando y practicando desde hace más de cuatro lustros, primero en la Maternidad Leopoldina de Santos del Hospital de Barranquilla y últimamente en el Hospital Universitario Metropolitano hasta la presente con buenos resultados.

El futuro obstétrico de la paciente, capaz de permitir el parto por vía vaginal, dependerá principalmente de las condiciones de la cicatriz uterina, lo que nos ha obligado a hacer una revisión de ésta, desde el punto de vista histológico, como clínico (4).

\section{Material y métodos}

Se seleccionaron para el presente estudio 64 pacientes que habían sido intervenidas con la técnica siguiente:

Una vez en contacto con la cavidad abdominal, se exponía el segmento uterino el cual era aislado. Con bisturí se practicaba una incisión horizontal de $1 \mathrm{~cm}$. del peritoneo visceral y segmento uterino, luego se continuaba abriendo la incisión con tijeras de vendaje hasta los bordes laterales del útero.

La separación del peritoneo del segmento solamente se realizaba en la zona correspondiente a la incisión. Una vez extraído el feto, se continuaba con la extracción de placenta y membrana, se instalaba una infusión de ocitocina, 10 
unidades por 500 de D. en agua destilada, con el fin de mantener el útero contraído y así evitar la pérdida de sangrado uterino, lo que permitía un mejor manejo del acto quirúrgico. Luego se exteriorizaba el útero, se tomaba con pinzas de Alix los ángulos de la incisión del segmento y se ponían en extensión para facilitar la sutura. En cada ángulo de la incisión se colocaba un punto en 8 invertido, se tomaba la muestra de la cicatriz de los bordes de la incisión y se enviaba para su estudio de patología. Se continuaba el cierre del segmento con puntos separados, utilizando catgut crómico $\mathrm{O}$. Este tipo de sutura permite un mejor afrontamiento de los bordes de la incisión y evita así una coaptación de la incisión del segmento uterino, lo que producirá un mejor restablecimiento de la circulación y una mejor regeneración de las fibras musculares de la incisión del segmento y por consiguiente una mejor cicatrización.

Terminado de cerrar la incisión del segmento, se procede a suturar el peritoneo con sutura continua con cromico 00 cero, sevisaba la sutura del segmento, se hacía limpieza de cavidad, se reintegraba útero a la cavidad abdominal y la pared abdominal se cerraba según la técnica habitual (Figuras Nos. 1-2-3)

Figura No. 1

\section{SEGMENTO ABIERTO, PUNTOS EN OCHO EN LOS EXTREMOS}

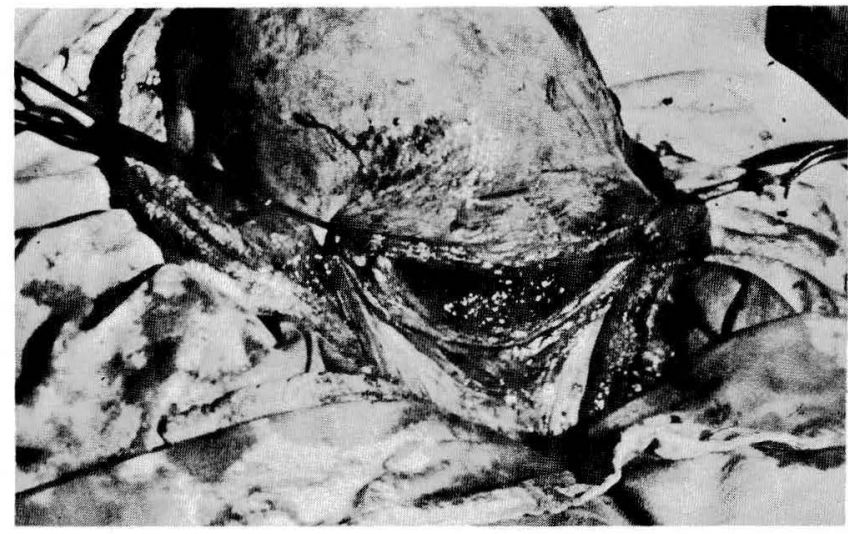

Figura No. 2

BIOPSIA DEL LABIO INFERIOR DEL SEGMENTO Y CIERRE CON PUNTOS SEPARADOS

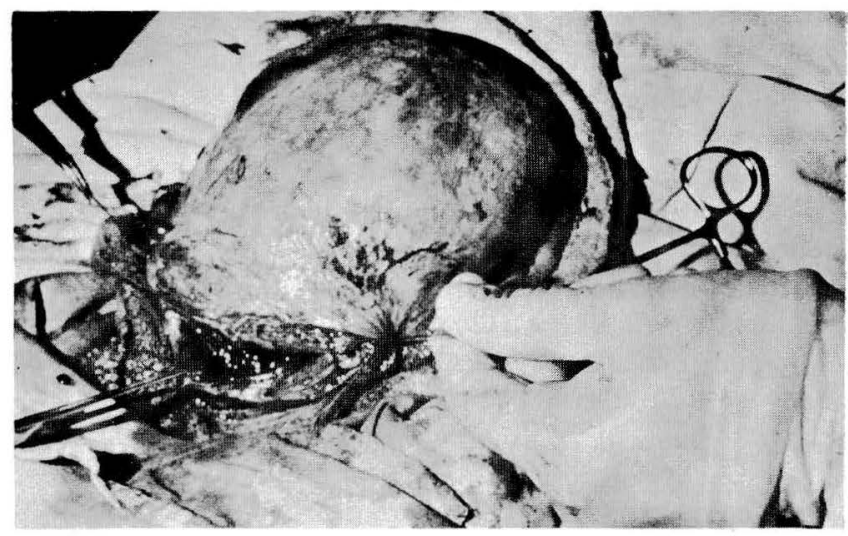

Figura No. 3

CIERRE COMPLETO DE SEGMENTO CON PUNTOS SEPARADOS Y PERITONEO

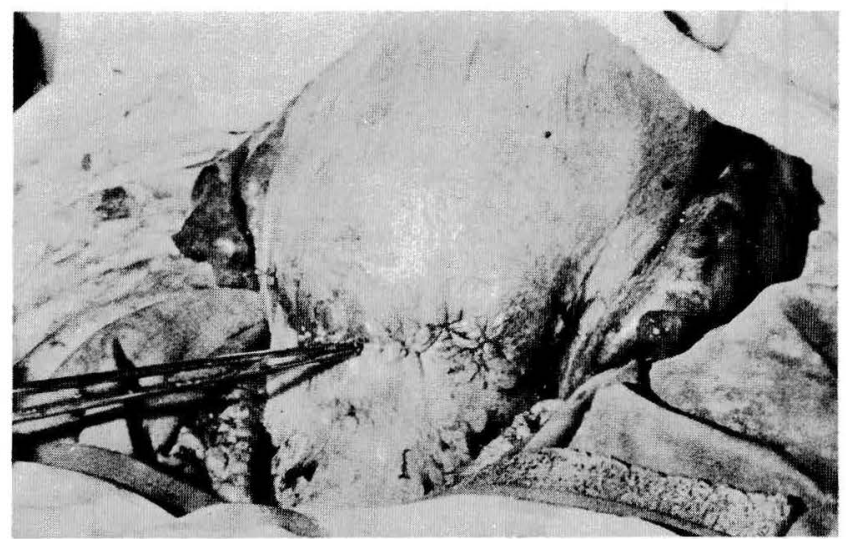

Figura No. 4

SEGMENTO UTERINO, NO SE IDENTIFICA LA CICATRIZ

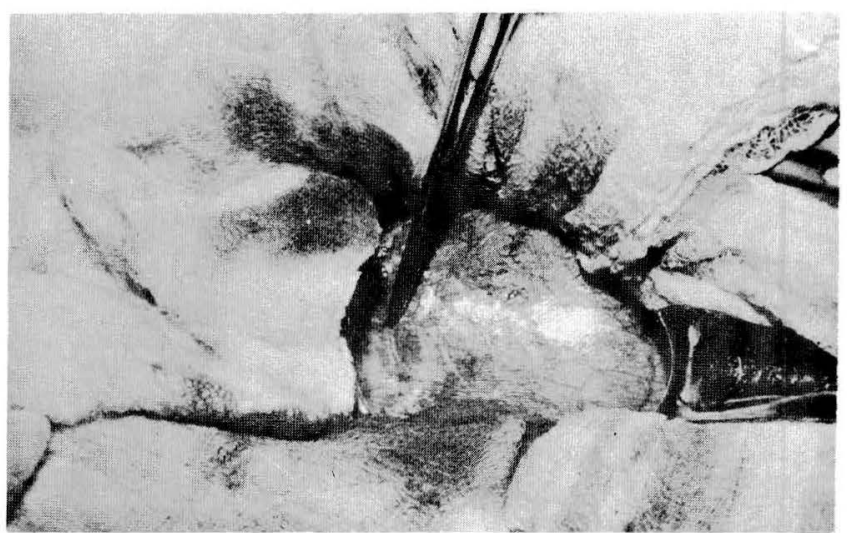

\section{Resultados}

Desde el punto de vista clínico sólo fue posible identificar la cicatriz en el $10 \%$ del total de los casos y desde el punto de vista histológico se observó una regeneración de las fibras musculares en el $67.12 \%$ del total de los casos de las cicatrices estudiadas.

Cuadro No. 1

ESTUDIO HISTOLOGICO DE LA CICATRIZ UTERINA

\begin{tabular}{cc}
\hline \multicolumn{2}{c}{ Cesáreas segmentarias } \\
\hline $\begin{array}{c}\text { No. de Cesáreas } \\
\text { Anteriores }\end{array}$ & $\begin{array}{c}\text { No. de } \\
\text { Casos }\end{array}$ \\
\hline 1 & 50 \\
2 & 11 \\
3 & 2 \\
4 & 1 \\
\hline Total & 64 \\
\hline
\end{tabular}

En el análisis del cuadro anterior registramos 50 casos con antecedentes de una sola cesárea, de las cuales $74 \%$ catalogadas como cicatrices buenas, $18 \%$ regulares y $8 \%$ como malas. 
En los casos de dos cesáreas anteriores se registraron $45 \%$ cicatrices buenas, $10 \%$ regulares y $45 \%$ malas.

En los casos con antecedentes de tres cesáreas se encontraron $50 \%$ con cicatriz buena y $50 \%$ con cicatriz mala.

En los casos con antecedentes de cuatro cesáreas, se rẹgistró un sólo caso con resultados de una cicatriz regular.

Cuadro No. 2

PORCENTAJE DEL TIPO DE CICATRIZ CON RELACION AL NUMERO DE CESAREA

\begin{tabular}{llccc}
\hline & & \multicolumn{3}{c}{ Tipo de cicatriz } \\
$\begin{array}{l}\text { No.de } \\
\text { Cesáreas }\end{array}$ & $\begin{array}{l}\text { No.de } \\
\text { Casos }\end{array}$ & Buena & Regular & Mala \\
Anteriores & & & & \\
\hline 1 & 50 & $74 \%$ & $18 \%$ & $8 \%$ \\
2 & 11 & $45 \%$ & $10 \%$ & $45 \%$ \\
3 & 2 & $50 \%$ & - & $50 \%$ \\
4 & 1 & - & $100 \%$ & - \\
\hline
\end{tabular}

En el cuadro anterior observamos un mayor porcentaje de cicatrices buenas y regulares, en pacientes con antecedentes de una sola cesárea. A medida que el número de cesáreas aumenta disminuye este porcentaje, sin embargo se registra un porcentaje significativo de cicatrices buenas en el resto de los casos de más de una cesárea lo que refleja el efecto favorable de la técnica de una sola sutura con puntos separados del segmento uterino.

Con relación a las cicatrices malas se observa un aumento progresivo coherente al número de cesáreas realizadas, excepto en el caso de cuatro (4) cesáreas anteriores en la cual se registra una cicatriz de tipo regular.

Catalogamos como cicatriz buena, cuando se encontró en el examen histológico una regeneración total del tejido muscular, regular cuando el proceso de cicatrización se registra con porcentajes iguales entre el tejido fibroso y el tejido muscular, y mala cuando la cicatriz presenta predominio del tejido fibroso sobre el tejido muscular.

Los datos anteriores nos demuestran que a medida que aumenta el número de cesáreas, se va produciendo a expensas del tejido muscular un mayor aumento del tejido fibroso y hialino en la mayor parte de las cicatrices (Figuras Nos. 5-6-7).

Figura No. 5

TEJIDO MUSCULAR LISO, VASOS DE NEOFORMACION Y CONGESTION, CON EXTRAVASACION DE ERITROCITOS, REGENERACION NORMAL, CATALOGANDOSE COMO CICATRIZ BUENA

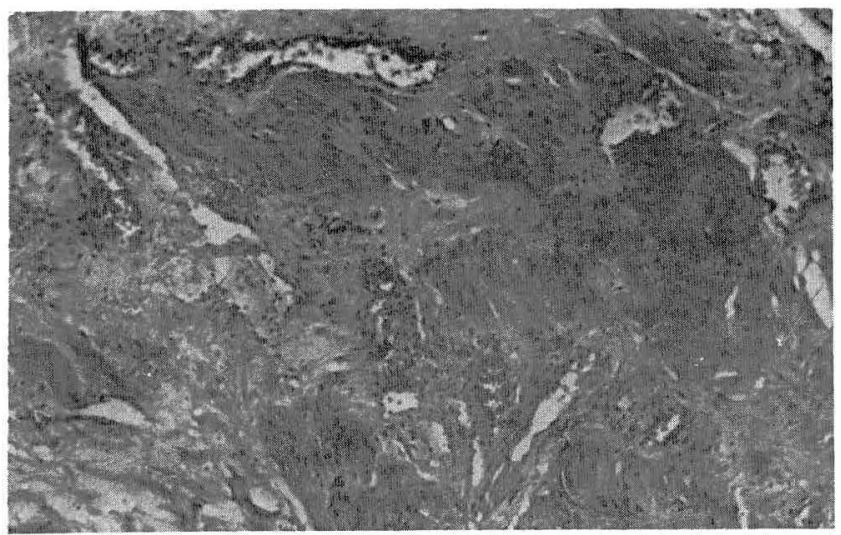

Figura No. 6

TEJIDO MUSCULAR CON HIALINIZACION MODERADA. CICATRIZ CATALOGADA REGULAR

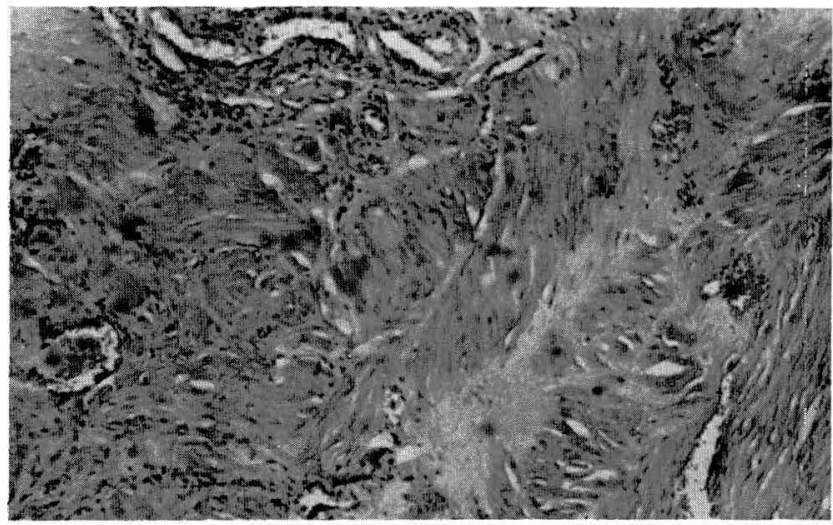

Figura No. 7

FIBROSIS MARCADA AUSENCIA DE TEJIDO MUSCULAR. CICATRIZ CATALOGADA MALA

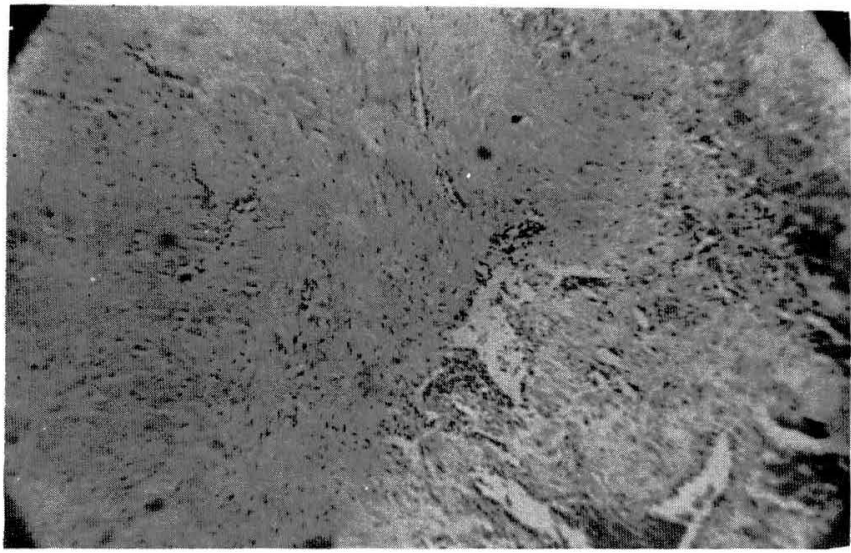

\section{Comentarios}

Desde el punto de vista de la patología, cuando se produce daño en algún tejido del cuerpo se presentan dos fenómenos:

1. La regeneración, que es la sustitución del tejido lesionado por células parenquimatosas del mismo tipo.

2. Sustitución por un estroma de tejido conectivo que va a constituir la cicatriz permanente.

En una cicatriz quirúrgica limpia se produce un número limitado de muerte celular, y la cicatrización ocurre con una mínima pérdida tisular. La resistencia de este tipo de heridas a la tracción guarda relación directa con la destreza quirúrgica y la colocación de puntos, necesitándose un promedio de un año para que la herida alcance su fuerza mecánica máxima con relación a la funcionabilidad del tejido lesionado.

De acuerdo con estudios realizados en los diferentes tipos de sutura, se ha comprobado que cuando se utilizan puntos separados se obtiene una mejor irrigación del tejido y por consiguiente una mejor cicatrización. Mientras con sutura continua se produce isquemia, con espacios muertos, alterando de esta manera el proceso de reparación y cicatrización.

En la revisión del presente estudio tanto clínica como histológica, se demuestra que la utilización de la técnica de 
una sola sutura con puntos separados del segmento uterino produce una mejor regeneración de las fibras musculares en la cicatrización del segmento, siempre y cuando se conserven los requisitos exigidos de una buena técnica quirúrgica.

Después de la segunda cesárea la cicatriz registra la presencia de tejido fibroso, hialino y muscular en proporciones desiguales con el consiguiente resultado de la presencia de una cicatriz uterina no garantizable para aconsejar el parto por vía vaginal.

El futuro obstétrico de las pacientes con antecedentes de cesárea está muy ligado a las condiciones de la cicatriz del segmento uterino, lo cual acondicionará la atención del parto, si debe hacerse por vía abdominal o vaginal.

En la revisión de las pacientes estudiadas tanto clínica como histológicamente, comprobamos una buena cicatrización del segmento uterino después de la primera cesárea con esta técnica, lo cual nos permite recomendar el parto por vía vaginal en pacientes con antecedentes de una cesárea anterior, teniendo en cuenta los parámetros que estos casos requieren para la atención del parto por esta vía.

Por las observaciones anteriores no es aconsejable la atención del parto por vía vaginal a partir de la tercera cesárea por la exposición de una ruptura o dehiscencia de la cicatriz, con el consiguiente riesgo para la paciente y el feto.

No registramos en el presente estudio, ningún caso de placenta previa, desprendimiento de placenta normalmente insertada, adherencia post-operatoria, como tampoco mortalidad fetal y materna.

\section{Agradecimientos}

A los doctores Silvio Severine y Marcos Rosillo, patólogos del Hospital Universitario Metropolitano por su contribución en este trabajo.

\section{BIBLIOGRAFIA}

1. J. Medrano M., Gabriel Acuña. Prueba de trabajo en pacientes con antecedentes de cesárea. Rev. Col. de Obstetricia y Ginecología. Volumen XXXIX No. 3 1988; 159-167.

2. E. Pineda Guerrero., Manuel Frías S., Jone Rober A., Ahmed A. Operación cesárea 25 años de su evolución en el H. Regional "20 de Noviembre" ISSSTE México Marzo 90 1990; 58: 65.

3. Lucas M. Machado. Fístulas vesico-cervicaes. Femina 1983. Vol II No. 10 pág. 843-888.
4. AJA Díaz Moragues., JLC Pinto E., Silva JA., Pinotti \& A. Faundes. Pronóstico Obstétrico E. Perinatal de Mulher Portadora de cicatriz de operacao cesariana Gin. Obst. Brasil. 1981; Vol. 4; p. 173.

5. Saldana LR., Schulman H. and Reuss L. Management of Pregnancy After Cesarian AM. J. Obstet. Gynecol. 1979; 135-155.

6. Morewood GA., O'Sullivan MJ \& McConey J. Vaginal Delivery after cesarian section. A.M.J. Obstet. Gynecol. 1973; 42: 589. 